\title{
Structure of hybrid organic-inorganic sols for the preparation of hydrothermally stable membranes
}

\author{
Hessel L. Castricum - Ashima Sah · Jan A. J. Geenevasen - Robert Kreiter • \\ Dave H. A. Blank · Jaap F. Vente $\cdot$ Johan E. ten Elshof
}

Received: 3 February 2008/ Accepted: 27 March 2008/Published online: 16 April 2008

(c) The Author(s) 2008

\begin{abstract}
A procedure for the preparation of hybrid sols for the synthesis of organic-inorganic microporous materials and thin film membranes is reported. We describe silane reactivity and sol structure for acid-catalysed colloidal sols from mixtures of either tetraethylorthosilicate (TEOS) and methyltriethoxysilane (MTES), or bis(triethoxysilyl)ethane (BTESE) and MTES. Early-stage hydrolysis and condensation rates of the individual silane precursors were followed with ${ }^{29} \mathrm{Si}$ liquid $\mathrm{NMR}$ and structural characteristics of more developed sols were studied with Dynamic Light Scattering. Condensation was found to proceed at more or less similar rates for the different precursors. Homogeneously mixed hybrid colloids can therefore be formed from precursor mixtures. The conditions of preparation under which clear sols with low viscosity could be formed from BTESE/MTES were determined. These sols were synthesised at moderate water/silane and acid/silane ratios and could be applied for the coating of defect-free microporous membranes for molecular separations under hydrothermal conditions.
\end{abstract}

H. L. Castricum · A. Sah · D. H. A. Blank · J. E. ten Elshof $(\bowtie)$ MESA+ Institute for Nanotechnology, University of Twente, P.O. Box 217, 7500 AE Enschede, The Netherlands

e-mail: j.e.tenelshof@utwente.nl

H. L. Castricum $(\bowtie)$ · J. A. J. Geenevasen

Van't Hoff Institute for Molecular Sciences, University of Amsterdam, Nieuwe Achtergracht 166, 1018 WV

Amsterdam, The Netherlands

e-mail: castric@science.uva.nl

R. Kreiter · J. F. Vente

Energy Research Centre of the Netherlands, Postbus 1, 1755 ZG Petten, The Netherlands
Keywords Silica - Organic-inorganic hybrid · Membrane - Microporous - Polymeric sol . Hydrothermal stability

\section{Introduction}

Microporous materials are of interest for a vast range of applications, including adsorption, fine chemical synthesis, oil refining and molecular sieving (e.g. desiccation). Solgel synthesis has proven to be a highly versatile technique for the preparation of high-purity microporous materials with well-controlled physical and chemical properties [15]. The applicability of sol-gel synthesis is especially apparent in functional materials, such as the ultra-thin coatings that can be used as molecular sieving membranes.

Molecular separations based on membrane technology are generally accepted as highly promising alternatives to existing technologies [4-11]. These separations are currently performed using (cryogenic) distillation or adsorption-based techniques, but their exergy efficiency is in general as low as $10 \%$. At the same time, they are responsible for an estimated $40 \%$ of the total energy consumption in the (petro)chemical industry worldwide, i.e. more than 10 billion barrels of oil equivalent per year. Unreliable long-term performance under industrial conditions is the main factor that has hampered actual implementation of membrane technology in molecular separation processes [12]. Various research groups have studied membranes consisting of microporous amorphous silica which are prepared by sol-gel technology. These membranes show good performance in gas separation and pervaporation applications and have a high thermal, mechanical and solvolytical stability $[4,5,13]$. However, the hydrothermal stability of pure silica is too low to ensure 
a reliable industrial application $[14,15]$, in the presence of water, even at moderate temperatures. The best results up to now have been obtained with silica materials in with part of the non-binding silanol groups have been replaced by non-binding organic group. The so-called 'methylated' silica membranes are prepared from a mixture of tetraethylorthosilicate (TEOS) and methyltriethoxysilane (MTES). Their stability is high enough to apply them up to an operating temperature of $95{ }^{\circ} \mathrm{C}$ in the dehydration of $n$-butanol [16]. Recently, it was shown that the replacement of siloxane bonds by binding organic linkers can lead to a membrane that can function stably up to $150{ }^{\circ} \mathrm{C}$ [12]. This new hybrid material is prepared from a combination of an organically linked precursor, such as bis(triethoxysilyl)ethane (BTESE), and methyltriethoxysilane (MTES). The high hydrothermal and structural stability have opened up the route towards practical industrial application of membrane technology in energy intensive separations.

Knowledge about the reactivity of the precursors is an important element for the preparation of homogeneous sol recipes. Initial stages of acid-catalysed hydrolysis have been studied by various authors [17-20]. Higher reaction rates have been observed with increasing water content and acidity. Van Bommel et al. [17] found higher hydrolysis and condensation rates for MTES than for TEOS. Still, MTES was not reported to show a shorter gelation time, which is probably due to the fact that number of reactive groups has been reduced from four in TEOS to three in MTES. Hook et al. [21] also observed an initially three times faster condensation for MTES, but found an equal extent of condensation in a later stage. The hydrolysis and initial stage of dimerisation were thoroughly studied for acid-catalysed TEOS and MTES [20]. Again a faster hydrolysis rate for MTES was observed. The rate of dimer formation was however higher for TEOS. The formation of random copolymers originating from TEOS/MTES mixtures was observed with ${ }^{29} \mathrm{Si}$ NMR $[19,20]$ and ${ }^{17} \mathrm{O}$ NMR [22]. The observations of Van Bommel [17] have led to the introduction of a prehydrolysis stage for the synthesis of TEOS/MTES-based membrane materials. Other studies $[19,20,22]$ thus suggest that such a procedure is not strictly required. To the best of our knowledge, no comparative study on the hydrolysis and condensation kinetics has yet been published for BTESE.

Here, we report a study on the sol-gel hydrolysis and condensation reactions, and colloid formation in sol synthesis using TEOS, MTES, and BTESE as precursors. Based on the common recipes for silica-based membranes, $\mathrm{HNO}_{3}$ was used as a catalyst. In the above-mentioned studies, $\mathrm{HCl}$ was applied. Hydrolysis and condensation of the different silane precursors were carried out under identical reaction conditions, i.e. with the same [Si] concentration, and $\left[\mathrm{H}^{+}\right]:[\mathrm{Si}]$ and $\left[\mathrm{H}_{2} \mathrm{O}\right]:[\mathrm{Si}]$ ratios. We also studied the sol structure from which the most promising organic-inorganic membranes are prepared, i.e. methylated silica [16, 23] and hybrid silica [12]. A combination of ${ }^{29} \mathrm{Si}$ NMR and Dynamic Light Scattering was applied to characterise both the early stage of synthesis and more developed sols, including the final sol that can be used for membrane preparation. This allowed us to review existing recipes for sol preparation, thereby focusing on the effect of a prehydrolysis step prior to mixing. We investigated whether the reactivities of the silane precursors indeed substantiate the assumptions made for the preparation of homogenously mixed methylated materials [17, 23]. Based on this, we attempted to predict whether there are opportunities to further improve the structure and hydrothermal stability of these materials. We also used our findings for the optimization of a hybrid material based on a mixture of BTESE and MTES precursors. For the latter mixture, we explored the influence of various preparation parameters on the colloid size of the sol. Our results on both the reactivity of the individual components and the structure of the homogeneous mixtures thereof can be used to further expand the potential of organic-inorganic materials for adsorption and molecular sieving applications.

\section{Experimental}

Tetraethylorthosilicate (TEOS, 99.999\% pure), methyltriethoxysilane (MTES, 99\% pure), 1,2-bis(triethoxysilyl) ethane (BTESE, 96\% pure) and dry ethanol were all obtained from Aldrich. These chemicals were used as received. Only BTESE was distilled before use to increase purity. Sols were prepared by the dilution of silanes in dry ethanol at $0{ }^{\circ} \mathrm{C}$, followed by the addition of diluted nitric acid ( $65 \mathrm{wt} . \%$, Aldrich). The nitric acid was added drop-wise to the diluted precursor under vigorous stirring. The sol was then refluxed in a water bath at $333 \mathrm{~K}$ under continuous stirring. For BTESE/MTES mixtures, half of the water was added after $1.5 \mathrm{~h}$ of refluxing. This was done after placing the sol in an ice bath and thermal equilibration. Subsequently, the sol was again placed in a water bath at $333 \mathrm{~K}$.

In situ ${ }^{29} \mathrm{Si}$ Nuclear Magnetic Resonance spectra were obtained from the sols from the individual precursors immediately after mixing with nitric acid and water. Synthesis was carried out under water-lean conditions at $[\mathrm{Si}]=1.8 \mathrm{M}, r_{\mathrm{a}}\left(\left[\mathrm{H}^{+}\right]:[\right.$silane $\left.]\right)=0.1$ and $r_{\mathrm{w}}\left(\left[\mathrm{H}_{2} \mathrm{O}\right]\right.$ : $[-\mathrm{OEt}])=0.25$ at a temperature of $273 \mathrm{~K}$. NMR spectra were acquired on a Bruker $500 \mathrm{MHz}$ NMR and referenced to tetramethylsilane. The pulse duration was $10 \mu \mathrm{s}$ ( $\sim 45^{\circ}$ pulse), and the repetition rate $2.5 \mathrm{~s}$. Tris(acetylacetonato)chromium(III) (0.1 wt.\%) was added to increase the demagnetization rate of the silicon nucleus. Hydrolysis was observed as a $\sim 1-2 \mathrm{ppm}$ downfield shift of the signal, 
and condensation ( $\mathrm{Si}-\mathrm{O}-\mathrm{Si}$ bond formation) by a $\sim 10$ ppm upfield shift $[17,19]$. Post-synthesis analyses of well-developed BTESE/MTES sols and TEOS sols were similarly carried out at $273 \mathrm{~K}$.

The hydrodynamic diameters of the colloids in the freshly prepared sols were determined in a $25 \%$ dilution in ethanol by Dynamic Light Scattering at $298 \mathrm{~K}$ in a Malvern Zetasizer Nano. From the Brownian motion of the particles in the solvent defined by the translational diffusion coefficient $D$, the hydrodynamic diameter $d$ was obtained by the Stokes-Einstein equation: $d=\mathrm{k} T / 3 \pi \eta D$, with k Boltzmann's constant, $T$ the temperature, and $\eta$ the viscosity of the solvent.

\section{Results and discussion}

\subsection{Hydrolysis and condensation rates}

The hydrolysis and condensation rates of TEOS, MTES and BTESE were determined by in situ ${ }^{29} \mathrm{Si}$ solution NMR. The collection of NMR data is hindered by the low abundancy of the ${ }^{29} \mathrm{Si}$ nucleus and its very slow demagnetization. For this reason the reaction kinetics were slowed down and determined at low temperature $(273 \mathrm{~K})$ under water-lean conditions. In addition, we added a small amount of $\mathrm{Cr}$ (III), which allowed us to increase the pulse rate with a factor of 50 and obtain sufficient signal-to-noise ratio.

Substantial differences in the initial hydrolysis rates were found (Table 1). This is in correspondence to earlier work that reported faster hydrolysis of MTES than TEOS by up to an order of magnitude $[17,21]$. This was the primary motivation for prehydrolysing TEOS prior to the addition of MTES in the preparation of sols for methylated silica membranes [23]. The electron-donating influence of $-\mathrm{CH}_{x}$ onto the $\mathrm{Si}$ atom is larger than that of $-\mathrm{OR}$. This enhances the proton-catalysed hydrolysis reaction, which involves complexation with the proton and subsequent loss of an alkoxygroup in the form of an alcohol. The hydrolysis rate increases from TEOS to BTESE to MTES. The electron-donating influence of $-\mathrm{CH}_{2}-\mathrm{CH}_{2}-$ is slightly smaller than that of $-\mathrm{CH}_{3}$, and the more bulky structure of BTESE may result in sterical hindrance and decreased accessibility

Table 1 Hydrolysis rates of three silane precursors, measured at [Si $]=1.8 \mathrm{M}, r_{\mathrm{a}}=0.1$ and $r_{\mathrm{w}}=0.25$ at $273 \mathrm{~K}$

\begin{tabular}{ll}
\hline Silane & Rate $\times 10^{3}\left(\mathrm{OH} / \mathrm{Si}, \mathrm{s}^{-1}\right)$ \\
\hline TEOS & 0.11 \\
MTES & 1.2 \\
BTESE & 0.42 \\
\hline
\end{tabular}

of the $\mathrm{Si}$ atom, with the result that BTESE hydrolyses at a lower rate than MTES.

The condensation rates of the three silanes differ initially, as can be recognised from the different slopes at $t=0 \mathrm{~s}$ (Fig. 1). At this point, there is hardly any connectivity (number of bonds between the moieties). The condensation rates became similar even before the average degree of condensation was such that one of the reactive groups had formed a bond with another moiety. At this stage, observable from the similar slopes in Fig. 1 at about $t=10 \mathrm{ks}$, the degree of condensation ( $\mathrm{Si}-\mathrm{O}-\mathrm{Si}$ bond formation) in polymerising MTES is only about $30 \%$ higher than in polymerising TEOS. A similar difference was found between MTES and BTESE (per silicon atom). Again, the higher condensation rate of MTES can be explained by the electron donating influence of the $-\mathrm{CH}_{x}$ groups on the $\mathrm{Si}$ atom. This promotes the formation of the positively charged $\mathrm{Si}-\mathrm{OH}_{2}^{+}$transition state, which results in faster condensation. However, the faster hydrolysis rate of MTES has a moderating effect, which is caused by the less electron-donating influence of the hydroxy-groups as compared to alkoxy. For the somewhat lower condensation rate of BTESE, as compared to MTES, a similar reasoning holds as for hydrolysis. Although Si in BTESE and MTES are chemically almost identical, the faster condensation kinetics of MTES as compared to BTESE is probably related to steric effects due to its (twice) smaller size as well as to electronic effects. The total of these effects was found to result in a similar condensation rate as for TEOS, within experimental error.

Dynamic Light Scattering (DLS) carried out on sols prepared under the same conditions revealed very small particles, near the lower limit of detection of the technique $(0.6 \mathrm{~nm})$. A relationship between colloid size and degree of condensation is shown in Fig. 2. The larger size for BTESE sols at a similar degree of condensation can be related to monomer size, which is about two times larger for BTESE. It becomes clear from these results that the condensation

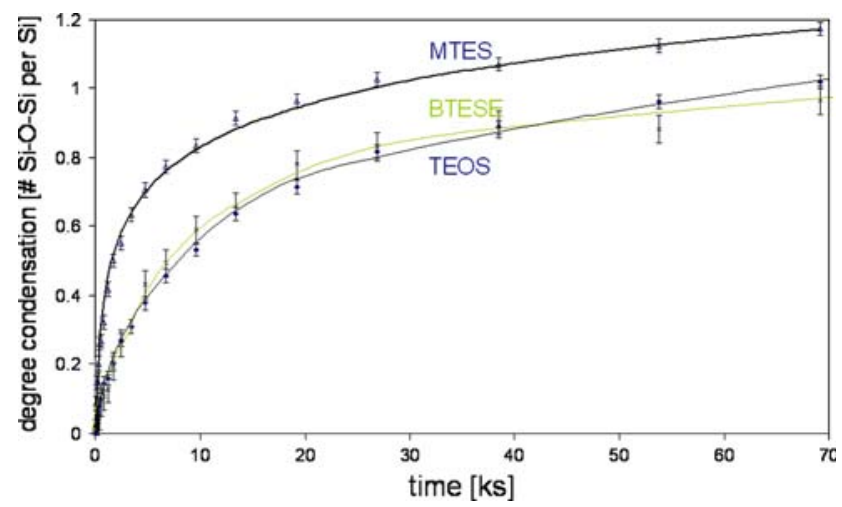

Fig. 1 Degree of condensation for three silanes (TEOS, MTES and BTESE) measured at $[\mathrm{Si}]=1.8 \mathrm{M}, r_{\mathrm{a}}=0.1$ and $r_{\mathrm{w}}=0.25$ at $273 \mathrm{~K}$ 


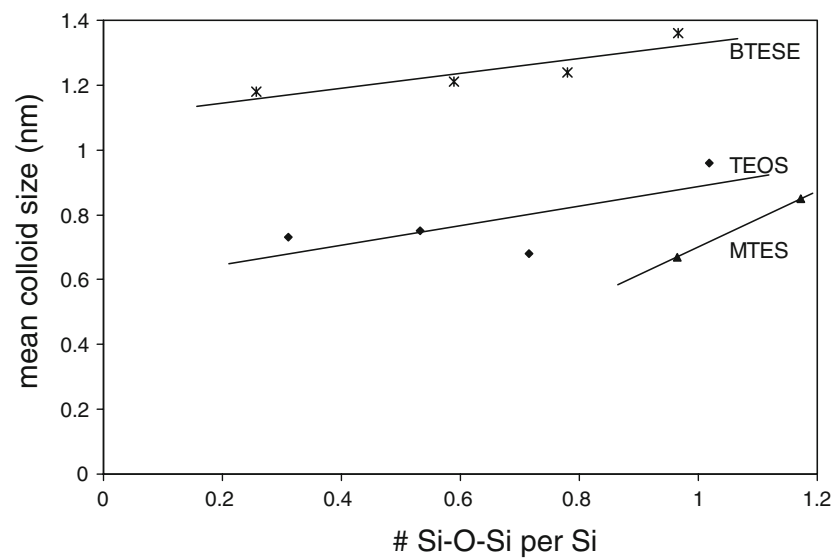

Fig. 2 Colloid sizes found with DLS after 1, 3, 6 and $24 \mathrm{~h}$ of synthesis compared to the degree of condensation determined with ${ }^{29} \mathrm{Si} \mathrm{NMR}\left([\mathrm{Si}]=1.8 \mathrm{M}, r_{\mathrm{a}}=0.1\right.$ and $r_{\mathrm{w}}=0.25$ at $\left.273 \mathrm{~K}\right)$

rates of all three monomers are more or less similar at the lowest particle size near the limit of detection of DLS.

\subsection{Methylated silica}

A prehydrolysis step has been included in synthesis procedures for the preparation of methylated silica membranes $[16,23]$. Selective membranes have been prepared from sols following two different routes. The 'one-step' route includes $165 \mathrm{~min}$ of TEOS hydrolysis at $333 \mathrm{~K}$ under water-rich and highly acidic conditions, with molar ratios TEOS: $\mathrm{C}_{2} \mathrm{H}_{5} \mathrm{OH}: \mathrm{HNO}_{3}: \mathrm{H}_{2} \mathrm{O}=1: 3.8: 0.085: 6.5 \quad[16,23]$. The 'two-step' route involves 90 min of TEOS prehydrolysis at $333 \mathrm{~K}$ under less water-rich conditions and at higher $\mathrm{pH}$, with a molar ratio TEOS: $\mathrm{C}_{2} \mathrm{H}_{5} \mathrm{OH}: \mathrm{HNO}_{3}$ : $\mathrm{H}_{2} \mathrm{O}=1: 3.8: 0.0036: 2.0$ [16]. After the prehydrolysis stage, MTES is added in both synthesis schemes, and in the 2-step procedure also water/acid is added. We studied the sol structure resulting from these two procedures after the first stage, i.e. just before the addition of MTES.

As can be seen from the results in Table 2, the difference between the two sols is substantial. The 1-step procedure resulted in sols with better connected moieties and larger colloid size than the 2-step procedure. Even more important is that the number of bonds is much greater than in the most developed TEOS sols investigated in the previous section. At the moment that MTES is added, a substantial number of bonds have thus already been formed, even for the less developed sol that was prepared via the 2-step route. The high degree of condensation is clearly related to the much higher synthesis temperature as compared to the temperature of $273 \mathrm{~K}$ applied in Sect. 3.1. If MTES had been added at the beginning of the process, the condensation rates of TEOS and MTES would have been comparable after similar preparation times. After addition of MTES and further synthesis, Gel Permeation Chromatography [16] had indicated a bimodal colloid size distribution for the one-step procedure, while a more homogeneous size distribution was found for sols prepared following the two-step procedure. Hence, the 1-step procedure results in a well-connected structure that does not fully allow the mixture to develop into a homogeneous copolymeric structure. Interestingly, despite the large differences between the sols prior to MTES addition, very little difference in performance and longevity were found between membranes prepared following the two routes for sol synthesis.

After coating and thermal treatment, the total degree of condensation of the TEOS/MTES materials is higher than 3 [16]. The degree of condensation is higher for the TEOS monomers $(\mathrm{Q})$ than for the MTES moieties $(\mathrm{T})$ in the 1-step procedure (Table 2). A better connected TEOS structure has thus been formed in the 1-step method, but at the expense of the MTES-connectivity. However, the differences are small. It was shown in the previous section that a degree of condensation of 1 is sufficient to obtain similar condensation rates. The most important factor that determines the degree of mixing of two silane precursors is their relative rate of condensation during the interval in which most bonds are formed. This also explains why various authors found that a random copolymeric structure could be formed from TEOS/MTES mixtures [19, 20, 22], despite the differences in initial reactivity. In the 2-step procedure, most bonds are formed after MTES addition, so that a homogenous structure can still develop. In the 1-step procedure, fewer connections remain to be formed after MTES addition, but some re-arrangements may take place

Table 2 Sol structure at the end of the TEOS prehydrolysis stage and connectivity of thermally consolidated gels from recipes for the preparation of methylated materials $[16,23]$

\begin{tabular}{|c|c|c|c|c|}
\hline \multirow[t]{3}{*}{ Sol recipe } & \multicolumn{2}{|c|}{ Sol (prior to MTES addition) } & \multicolumn{2}{|c|}{ Gel (after calcination) } \\
\hline & \multirow[t]{2}{*}{ Mean $d_{\text {colloid }}(\mathrm{nm})$} & \multicolumn{3}{|c|}{ Condensation degree (Si-O-Si per $\mathrm{Si})$} \\
\hline & & Q & Q & $\mathrm{T}$ \\
\hline 1 step & 6.5 & 2.8 & 3.65 & 2.51 \\
\hline 2 step & 1.2 & 1.8 & 3.35 & 2.64 \\
\hline
\end{tabular}

The connectivity of the sols was determined with liquid ${ }^{29} \mathrm{Si} \mathrm{NMR}$ and that of the gels with ${ }^{29} \mathrm{Si}$ MAS-NMR [16] 
due to thermally-induced breaking and re-creation of $\mathrm{Si}-\mathrm{O}-\mathrm{Si}$ bonds. This could explain why very few differences have been observed between membrane materials prepared according to these two procedures. A high degree of homogeneity has even been found for MTES/TEOS gels after the 1-step route [24].

Considering the high degree of condensation of TEOS moieties before MTES addition, attained even with the '2-step' route, it can be argued that a more homogeneous mixture and random organic-inorganic copolymeric structure would be obtained without a prehydrolysis stage. High MTES concentrations were found to result in mesoporous 'defects' in membranes and no selective membranes have yet been prepared with an MTES concentration exceeding 50 mol\% [16, 23]. In fact, membranes with 50\% MTES were somewhat less selective towards the transport of small molecules than purely inorganic membranes [23]. Mesopores of around $2 \mathrm{~nm}$, which may act as defects depending on the application in which the membrane is used, have also been observed in unsupported gels prepared from MTESrich mixtures. These mesopores were suggested to be related to phase separation into hydrophobic (methyl-rich) and hydrophilic (methyl-lean) regions [24]. Our present findings suggest that the structure of methylated silica sols may be improved by mixing the silanes at an earlier moment or by even completely omitting the prehydrolysis stage. However, as an upper limit of 50\% MTES has also been observed on defect-free membrane materials that had been made by a procedure that did not include TEOS prehydrolysis [25], further improvements will likely require careful tuning of the recipe and thorough sol characterisation.

\subsection{Hybrid silica}

The high hydrothermal stability of microporous membrane materials prepared from BTESE/MTES mixtures is related to the high fracture resistance of BTESE-based materials [12]. This is also advantageous for the preparation of crackand defect-free thin layers. Our motivation for working with a mixture of BTESE and MTES instead of with pure BTESE was twofold. The first reason was that the incorporation of methyl groups would help to 'shield' the siloxane bonds from water, similar as in TEOS/MTESbased materials [16], making them even less sensitive towards hydrolysis. The second reason was related to the extensive formation of cyclic carbosiloxane structures from bridged silanes that has been reported [26]. These structures reduce the level of functionality and do not contribute to 3D network formation. Our hypothesis was that the addition of MTES would lower the statistical chance of formation of inert cyclic structures and lead to a more open porous structure. In a similar way, larger pore volumes have been observed upon the addition of MTES to TEOS [24].
Our observations in Sect. 3.1 show that the condensation rates of TEOS and MTES differ as much as those of BTESE and MTES. As we found that a statistically random copolymer can be formed from TEOS/MTES upon full condensation, this should also hold for BTESE/MTES. This also means that auto-condensation of BTESE is suppressed by addition of MTES. In view of our findings for TEOS/MTES, we considered that a prehydrolysis step prior to addition of the second silane is not strictly required. Similar as for TEOS/MTES, the condensation rates of MTES and BTESE differ only in the earliest stage during which very few connections are made, and most of the network is formed at roughly equal condensation rates. We found that this procedure resulted in the synthesis of a hybrid material with an open microporous structure, no mesopores, and good molecular separation ability [12]. The separation performance, defined as flux times selectivity, was even better than for methylated silica membranes.

A good indication of the structural development of sols from mixtures of BTESE and MTES was obtained with Dynamic Light Scattering (DLS). Figure 3 shows the colloid size distribution as a function of reaction time for a mixture with $r_{\mathrm{w}}=0.5$. Water-lean conditions were employed in the first stage of synthesis to limit fast (exothermic) hydrolysis. A second water addition step was required to allow full development of the colloids. A sharp increase in growth rate was observed after addition of water at $t=90 \mathrm{~min}$. The growth rate was found to be related to the total amount of water added to the sample.

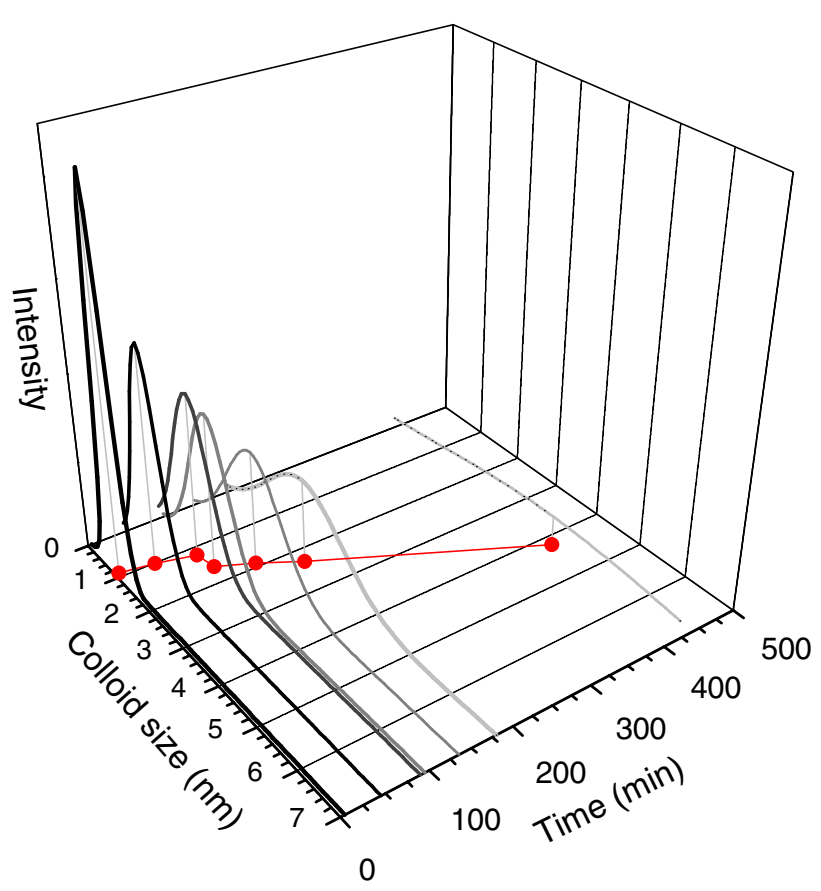

Fig. 3 Colloid size distribution plotted against reflux time for a sol from a BTESE/MTES mixture with $r_{\mathrm{w}}=0.5$ 
Quantitative ${ }^{29}$ Si NMR analyses of the overall condensation rate could not be carried out on sols from mixtures of BTESE and MTES, because of extensive overlap of peaks. However, we could observe the effect of the second water addition step for a mixture with a (final) $r_{\mathrm{w}}$ of 0.5. While uncondensed Si species $\left(\mathrm{T}_{0}\right)$ were still present after $90 \mathrm{~min}$ of refluxing, we observed the complete disappearance of these species within minutes after the second addition of water (Fig. 4). At the same time, the downfield components of dimers $\left(\mathrm{T}_{1}\right)$ and trimers $\left(\mathrm{T}_{2}\right)$ became more prominent, indicating hydrolysis of these units. Thus, the reactivity towards further condensation increased strongly upon addition of more water by the presence of more $-\mathrm{OH}$ groups. A concomitant discontinuity in colloid size development was observed with DLS between 90 and 95 min (Fig. 3). Thus, by limiting the availability of water in an early stage, the (co)polymeric structure develops more gradually. At a later stage, the size of the sol particles can be further tuned by adjusting the total amount of added water. After addition, water rapidly hydrolysed remaining ethoxy groups, which resulted in an increased reactivity towards condensation and faster growth of the colloids.

Larger colloids were observed not only after longer reaction times and higher values of $r_{\mathrm{w}}$, but it was also possible to tailor the colloid size by increasing $r_{\mathrm{a}}$. Recipes covering a range of acid and water concentrations were studied to define the range in which suitable sols can be prepared. Clear sols were obtained from all investigated BTESE/MTES mixtures, whereas acid-catalysed hydrolysis and condensation of pure MTES eventually resulted in the formation of precipitates. Hence, the clear sols were another indication for the formation of a truly copolymeric structure. The mean sol colloid sizes of all studied recipes are shown in Fig. 5. Low viscosity sols were formed at $r_{\mathrm{a}} \leq 0.1$ and $r_{\mathrm{w}} \leq 1$. More viscous sols were found for sols with $r_{\mathrm{a}}=0.32$ and $r_{\mathrm{w}}=1$, and $r_{\mathrm{a}}=0.1$ and $r_{\mathrm{w}}=2$.

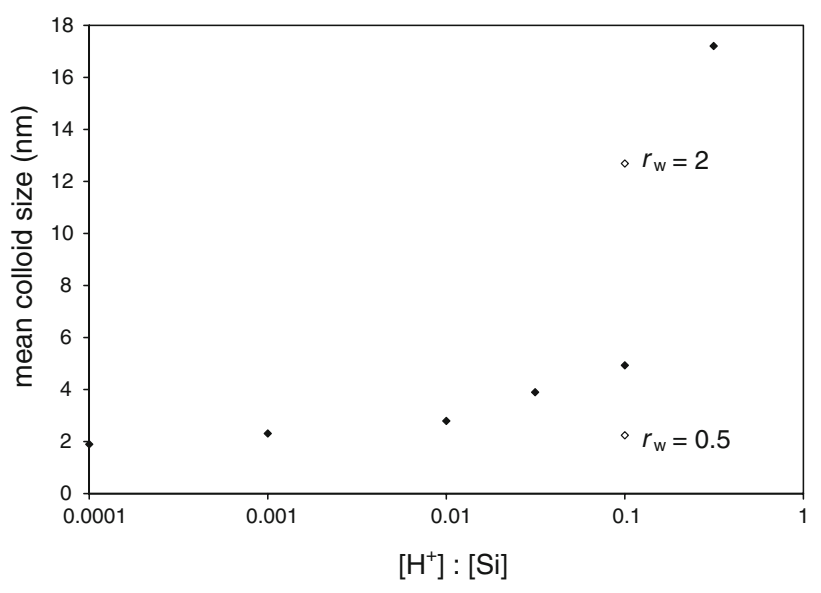

Fig. 5 Mean colloid sizes determined by averaging over the population according to scattering intensity. Sols were prepared from BTESE and MTES with total [Si] $=1.8 \mathrm{M}$, after $3 \mathrm{~h}$ reflux at $333 \mathrm{~K}$ and addition of half of the total amount of water at $r_{\mathrm{w}}=1$ (unless otherwise indicated) after 90 minutes

Brittle gels formed under the latter two conditions in case all water was supplied at once. Thin continuous defect-free films could be synthesised (Fig. 6) from low viscosity sols with colloid sizes around the pore size of the support $(5 \mathrm{~nm})$, and applied as molecular sieving membranes [12]. Figure 6 shows that a limited spread exists in the applicable concentration ranges, which are basically centered around $r_{\mathrm{a}}=0.1$ and $r_{\mathrm{w}}=1$. We expect that a large class of other microporous materials and thin films can be designed with similar methods as described here.

\section{Conclusions}

The initial hydrolysis and condensation rates of tetraethylorthosilicate, methyltriethoxysilane and bis(triethoxysilyl)ethane under acidic conditions were determined with
Fig. $4{ }^{29} \mathrm{Si}$ NMR patterns of a BTESE/MTES sol with $r_{\mathrm{w}}=0.5$ after a reflux time of 90 and 95 minutes (after water addition). Arrows highlight the vanished $\mathrm{T}_{0}$ peaks and the increased downfield contributions of $T_{1}$ and $T_{2}$ regions that indicate more extensive hydrolysis. As the $\mathrm{T}_{0}$, $\mathrm{T}_{1}$ and $\mathrm{T}_{2}$ spectral regions of the two individual silanes show some overlap, a rough indication of the regions is given below the figure

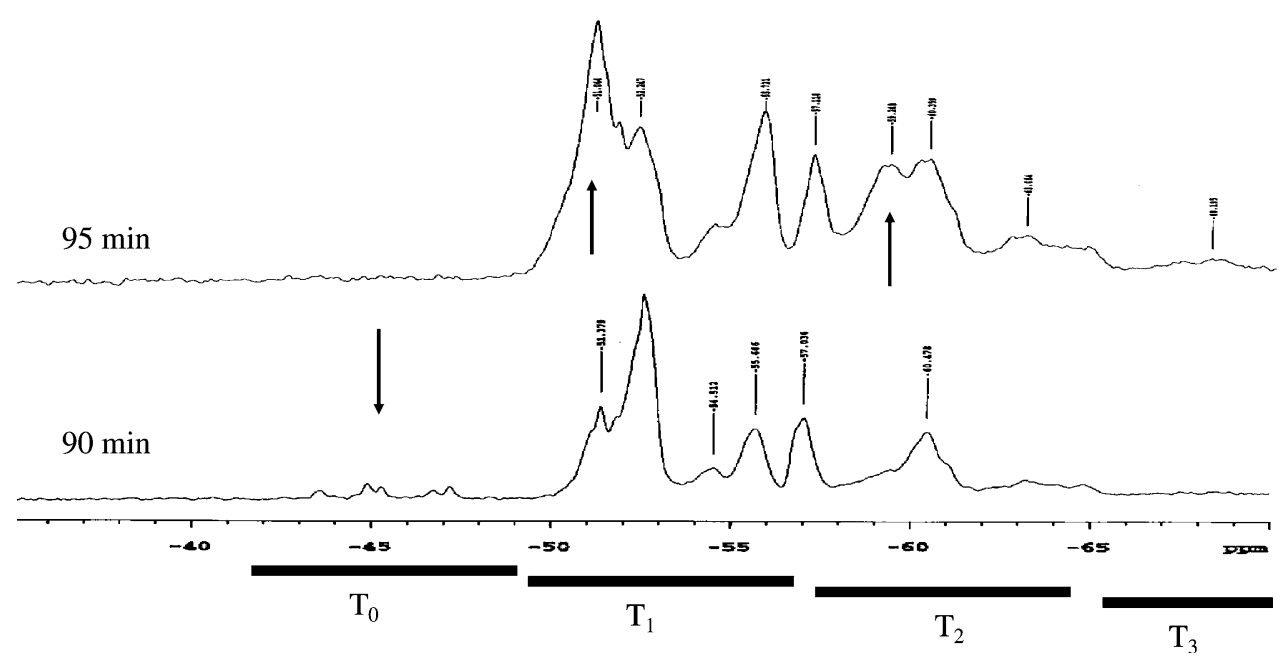




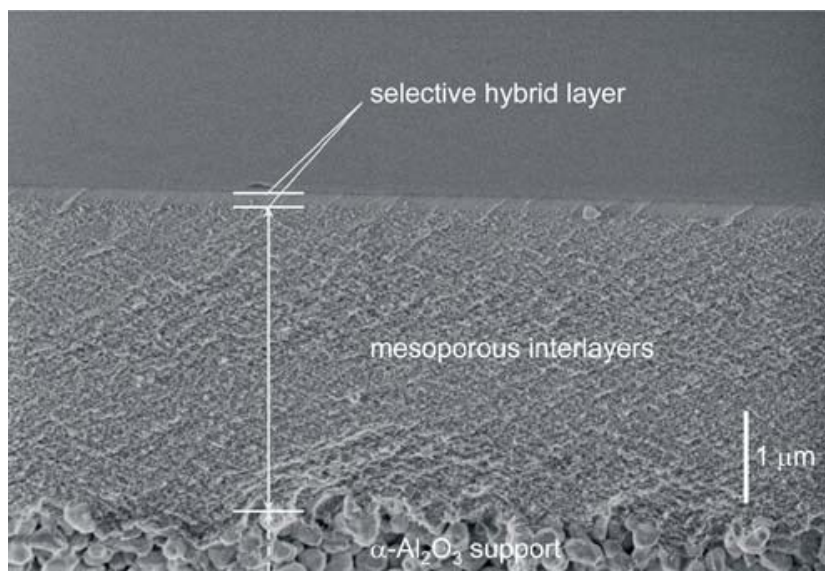

Fig. 6 Cross-sectional SE Micrograph of a hybrid composite membrane, showing the supporting layers and the coated hybrid silica top layer (thickness $\sim 0.1 \mu \mathrm{m}$ ) [12]

${ }^{29}$ Si liquid NMR. While hydrolysis rates differed by up to one order of magnitude, condensation was found to proceed at similar rates after a short induction period. This indicates that homogeneous random copolymeric colloids can be synthesised from both TEOS/MTES and BTESE/MTES mixtures. We found no indication that the structure of a homogenously mixed material is improved by including a prehydrolysis step of the less reactive silane. Sols from BTESE/MTES mixtures were characterised with Dynamic Light Scattering. The colloid size gave a good indication of the degree of sol development. The preparation window within which homogeneous sols with low viscosity could be synthesised was determined. Defect-free thin films could be prepared from low-viscosity sols with colloid sizes of about the pore size of the support. They can be applied as selective membranes for molecular separation.

Acknowledgements Financial support from the Netherlands Technology Foundation STW and the EOS technology programme of the Dutch Ministry of Economic Affairs is gratefully acknowledged. We thank Marjo Mittelmeijer-Hazeleger for technical assistance and Jan Meine Ernsting and Lidy van der Burg (University of Amsterdam) for assistance in the NMR measurements.
Open Access This article is distributed under the terms of the Creative Commons Attribution Noncommercial License which permits any noncommercial use, distribution, and reproduction in any medium, provided the original author(s) and source are credited.

\section{References}

1. Kessler VG, Spijksma GI, Seisenbaeva GA et al (2006) J Sol-Gel Sci Technol 40:163

2. Hall MM, Clare AG (2007) J Sol-Gel Sci Technol 41:107

3. Lim C, Hong SI, Kim H (2007) J Sol-Gel Sci Technol 43:35

4. de Vos RM, Verweij H (1998) Science 279:1710

5. de Vos RM, Verweij H (1998) J Membr Sci 143:37

6. Vane LM (2005) J Chem Technol Biotechnol 80:603

7. Duke MC, da Costa JCD, Do DD et al (2006) Adv Funct Mater 16:1215

8. Cot L, Ayral A, Durand J et al (2000) Solid State Sci 2:313

9. Lai ZP, Bonilla G, Diaz I et al (2003) Science 300:456

10. Lin HQ, Van Wagner E, Freeman BD et al (2006) Science 311:639

11. Sommer S, Melin T (2004) Ind Engin Chem Res 43:5248

12. Castricum HL, Sah A, Kreiter R et al (2008) Chem Commun 1103

13. Uhlhorn RJR, Van Vuren RJ, Burggraaf AJ (1988) J Membr Sci 39:285

14. Imai H, Morimoto H, Tominaga A et al (1997) J Sol-Gel Sci Technol 10:45

15. Iler RK (1979) The chemistry of silica. Wiley \& Sons Inc., New York

16. Campaniello J, Engelen CWR, Haije WG et al (2004) Chem Commun 834

17. Van Bommel MJ, Bernards TNM, Boonstra AH (1991) J NonCryst Solids 128:231

18. Sugahara Y, Okada S, Sato S et al (1994) J Non-Cryst Solids $167: 21$

19. Sugahara Y, Inoue T, Kuroda K (1997) J Mater Chem 7:53

20. Fyfe CA, Aroca PP (1997) J Phys Chem B 101:9504

21. Hook RJ (1996) J Non-Cryst Solids 195:1

22. Prabakar S, Assink RA, Raman NK et al (1996) J Non-Cryst Solids 202:53

23. de Vos RM, Maier WF, Verweij H (1999) J Membr Sci 158:277

24. Castricum HL, Sah A, Mittelmeijer-Hazeleger MC et al (2007) J Mater Chem 17:1509

25. da Costa JCD, Lu GQ, Rudolph V (2001) Colloids Surf A 179:243

26. Shea KJ, Loy DA (2001) Acc Chem Res 34:707 